Abstracta Iranica Abstracta Iranica

Revue bibliographique pour le domaine irano-aryen

Volume 42-43 | 2021

Comptes rendus des publications de 2019-2020

\title{
Cailah Jackson. Islamic Manuscripts of Late Medieval Rūm, 1270s-1370s : Production, Patronage and The Arts of the Book
}

Frantz Chaigne

\section{(2) OpenEdition \\ Journals}

Édition électronique

URL : https://journals.openedition.org/abstractairanica/52106

DOI : 10.4000/abstractairanica.52106

ISSN : 1961-960X

Éditeur :

CNRS (UMR 7528 Mondes iraniens et indiens), Éditions de l'IFRI

Référence électronique

Frantz Chaigne, «Cailah Jackson. Islamic Manuscripts of Late Medieval Rūm, 1270s-1370s : Production, Patronage and The Arts of the Book», Abstracta Iranica [En ligne], Volume 42-43| 2021, document 2, mis en ligne le 30 décembre 2020, consulté le 13 décembre 2022. URL : http://journals.openedition.org/ abstractairanica/52106 ; DOI : https://doi.org/10.4000/abstractairanica.52106

Ce document a été généré automatiquement le 13 décembre 2022.

Tous droits réservés 


\title{
Cailah Jackson. Islamic Manuscripts of Late Medieval Rūm, 1270s-1370s : Production, Patronage and The Arts of the Book
}

\author{
Frantz Chaigne
}

\section{RÉFÉRENCE}

Cailah Jackson. Islamic Manuscripts of Late Medieval Rūm, 1270s-1370s : Production, Patronage and The Arts of the Book. (Edinburgh Studies in Islamic Art). Edimbourg : Edinburgh University Press, 2020, 306 p, ill., biblio., ind. [ISBN : 978-1-4744-5148-2]

1 Dans cet ouvrage issu de sa thèse, Cailah Jackson se penche sur les divers aspects de la production de manuscrits en Anatolie à une époque politiquement complexe. En effet, le contexte historique est particulièrement troublé et mouvant pour cette région aux marges de l'empire îl-khānide. À ce propos, notons d'emblée que la contextualisation est ici abordée de façon magistrale. Il convient tout d'abord de signaler que l'auteure ne s'intéresse ici qu'aux manuscrits enluminés (i.e. non illustrés). Le corpus d'étude se limite à quinze manuscrits, ce qui permet de ne retenir que des items datés ou datables, tous décrits de façon détaillée dans le catalogue (données codicologiques, informations collectées dans les colophons, ...). Manquent peut-être les descriptions des programmes d'enluminures dans ce catalogue mais ceux-ci peuvent être restitués par la lecture du corpus et surtout par la très abondante et remarquable iconographie, toute en couleurs.

Dans l'introduction, l'auteure s'attache à montrer le caractère fluctuant du territoire de Rūm, signalant le caractère inopérant d'une approche dynastique dans cette étude. Ainsi, pendant la première phase de la période étudiée, la région est placée sous domination îl-khānide directe. Les apports de la codicologie et la nécessité d'étudier les 
sources primaires disponibles (chroniques, actes de waqf, etc., rédigés en arabe ou en persan) sont aussi signalés. Le premier chapitre présente la production régionale sous domination mongole, avec en particulier une étude comparative poussée d'un coran et d'un masnavi tous deux copiés en 1278 à Konya et ornés par le même enlumineur. Ce chapitre montre d'emblée la nécessité de croiser descriptions des enluminures, données des colophons et comparaisons avec des productions externes, prouvant par exemple les conditions production, les mobilités d'artisans et les phénomènes de convivence. Des rapports sont alors clairement établis avec la production iranienne contemporaine. Le deuxième chapitre se focalise sur les productions de Sivas et Konya dans un nouveau contexte de patronage turcoman. S'inscrivant en continuité avec le premier chapitre, se pose ici l'existence de ce que Jackson convient d'appeler une «école de Konya " possédant des programmes enluminés caractéristiques et pérennes. Le troisième chapitre évoque la production plus modeste de "miroirs des princes " issus de la région occidentale de Rūm. Enfin, le quatrième chapitre s'arrête sur la production liée à un unique commanditaire de l'époque la plus tardive, mettant en exergue l'intérêt des études à une micro-échelle. L'auteure prouve donc que loin d'être des villes perdues aux marges du monde islamique, Konya a su être un centre actif, sachant par exemple tirer parti de sa proximité des mondes chrétiens et d'empires islamiques divers, mamelouk ou persan, assumant ainsi un rôle nodal.

En conclusion, Cailah Jackson démontre ici clairement la nécessité de croiser informations codicologiques, études de décor, données historiques. Son approche sur des courtes périodes et des régions d'étendues réduites permet de comprendre au plus près les vocabulaires ornementaux, les contextes de production et la sociologie de la création - artisans et commanditaires - sur des micro-échelles. Une telle méthode se montre donc particulièrement opérante ainsi que Nourane Ben Azzouna l'avait démontré dans son ouvrage Aux origines du classicisme qui portait sur la production manuscrite dans l'Iran sous domination mongole.

\section{AUTEURS}

\section{FRANTZ CHAIGNE}

Chercheur associé à l'UMR 8167 « Islam médiéval » 